\title{
Karyopherin alpha 2 expression is a novel diagnostic and prognostic factor for colorectal cancer
}

\author{
LEI YU ${ }^{1,2^{*}}$, GUIYU WANG ${ }^{1,2^{*}}$, QIAN ZHANG ${ }^{1,2}$, LI GAO $^{3}$, RUI HUANG ${ }^{1,2}$, YINGGANG CHEN ${ }^{1,2}$, \\ QINGCHAO TANG ${ }^{1,2}$, JIN LIU $^{4}$, CHUNJIA LIU ${ }^{5}$, HONGWEI WANG ${ }^{1}$ and XISHAN WANG ${ }^{6}$ \\ ${ }^{1}$ Department of Colorectal Surgery, The Second Affiliated Hospital of Harbin Medical University; ${ }^{2}$ Department of Pathology, \\ Colorectal Cancer Institute of Harbin Medical University; Departments of ${ }^{3}$ Oral Surgery and ${ }^{4}$ Pathology, \\ The Second Affiliated Hospital of Harbin Medical University, Harbin, Heilongjiang 150086 ; ${ }^{5}$ Department of \\ Histology and Embryology, Basic Medical Science College, Harbin Medical University, Harbin, Heilongjiang 150001; \\ ${ }^{6}$ Department of Colorectal Surgery, Cancer Hospital of Chinese Academy of Medical Sciences, Beijing 100021, P.R. China
}

Received March 22, 2015; Accepted April 15, 2016

DOI: $10.3892 / \mathrm{ol} .2017 .5579$

\begin{abstract}
Colorectal cancer (CRC) is the fourth most common cancer and the second leading cause of cancer-associated mortality in Western countries. CRC treatment is dependent on the preoperative and postoperative condition of patients. At present, the prognostic value of conventional parameters for the estimation of patient prognosis is limited. The aim of the present study was to investigate the expression of karyopherin $\alpha 2$ (KPNA2) in cancerous and healthy colon tissues and to evaluate the prognostic factors for patients with primary CRC. KPNA2 expression in CRC and paired normal tissues was analyzed by immunohistochemistry and reverse transcription-quantitative polymerase chain reaction (RT-qPCR). In addition, serum KPNA2 expression was evaluated by enzyme-linked immunosorbent assay. Subsequently, the association between KPNA2 expression in CRC tissues and patient clinicopathological features was analyzed. Kaplan-Meier analysis was utilized to investigate the prognostic value of KPNA2 expression on overall survival rates following radical surgery for the treatment of CRC. Immunohistochemistry and RT-qPCR revealed that KPNA2 expression was significantly increased in CRC tissues compared with paired normal tissues. Serum KPNA2 expression was significantly increased in CRC patients compared with healthy individuals. Furthermore, KPNA2 expression was observed to positively correlate with Tumor-Node-Metastasis stage, lymph node involvement,
\end{abstract}

Correspondence to: Professor Xishan Wang, Department of Colorectal Surgery, Cancer Hospital of Chinese Academy of Medical Sciences. 17 Panjiayuannanli, Beijing 100021, P.R. China

E-mail: hmu_dr_xswang@yeah.net

*Contributed equally

Key words: colorectal cancer, karyopherin $\alpha 2$, diagnosis, prognosis, postoperative survival, oncogene tumor differentiation, infiltration depth, lymphovascular invasion and perineural invasion, which are factors known to affect the prognosis of CRC patients following surgery. In addition, increased KPNA2 expression was associated with decreased overall survival and disease-free survival rates. Patients not suited for surveillance regimens may be identified at initial biopsy test with a positive KPNA2 immunohistochemistry. Increased serum expression of KPNA2 may be utilized as a diagnostic factor for patients with CRC. High nuclear KPNA2 expression may serve as a novel predictor of survival following radical colorectal surgery in CRC patients. The results of the present study may improve individualized risk stratification, leading to the optimization of therapies for CRC patients.

\section{Introduction}

Colorectal cancer (CRC) is the fourth most common cancer and the second leading cause of cancer-associated mortality in the United States. Although the incidence and mortality rates of CRC have decreased in recent decades as a result of earlier diagnosis, >10,000 new cases are diagnosed annually in the USA (1).

The efficacy of CRC treatment is dependent on the preoperative condition of patients, which includes the local depth of tumor incision ( $\mathrm{T}$ stage), lymph-node metastasis ( $\mathrm{N}$ stage) and the histological grade of tumors (1). Although useful, in certain cases these factors fail to differentiate tumors from each other, which is important for CRC patients with lymph node metastasis that require adjuvant chemotherapy following curative resection (1). However, certain patients may not benefit from additional therapy (1). As a result, the identification of a biomarker that accurately corresponds with the various stages of CRC is urgently required.

Dysfunction of the cellular transport machinery is common in cancer cells, and this observation has led to the development of therapies that target this machinery (2). Karyopherin $\alpha$ (KPNA) belongs to a family of nuclear transport proteins, which interact with cellular cargo via the nuclear localization signal $(3,4)$. In addition to combined action, importin $\alpha$ also binds the nuclear cargoes directly without the assistance of 
importin $\beta$ (5). As a member of the KPNA family, KPNA2 is a $58 \mathrm{kDa}$ protein composed of 529 amino acids $(5,6)$. A change of bowel habit and blood in the stool are most common symptoms in patients with CRC. Although the cause of CRC is remains unclear, certain health history can affect the risk of developing $\mathrm{CRC}$, including a family history of CRC, certain hereditary conditions (Lynch syndrome), a history of ulcerative colitis and polyps in the colon and rectum.

A number of studies have demonstrated that KPNA2 is expressed at a high level in a variety of types of cancer, including breast and lung (7-11). However, few studies have investigated the expression of KPNA2 in CRC. Therefore, the aim of the present study was to analyze KPNA2 expression in malignant colorectal tumors and to elucidate its function as an oncogene in CRC.

\section{Materials and methods}

Ethics statement. All protocols were reviewed and approved by the Ethical Committee of Harbin Medical University (Harbin, China) and written informed consent was obtained from all participants.

Patients and tissue preparation. A total of $30 \mathrm{CRC}$ patients (15 males and 15 females; mean age, 56.4 years) diagnosed with colorectal adenocarcinoma (stage I-IV), who received surgical treatment at the Second Affiliated Hospital of Harbin Medical University (Harbin, China) between January 2014 and June 2014, were enrolled in the present study, as well as 30 healthy volunteers (15 males and 15 females; mean age, 59.1 years). None of the patients had previously undergone neoadjuvant treatment. For enzyme-linked immunosorbent assay (ELISA), preoperative venous blood $(10 \mathrm{ml})$ was collected from each participant and centrifuged $(1006.2 \mathrm{x} \mathrm{g})$ at $4^{\circ} \mathrm{C}$ for serum collection. The serum samples collected were stored at $-80^{\circ} \mathrm{C}$ until additional analysis occurred. For reverse transcription-quantitative polymerase chain reaction (RT-qPCR), cancerous and paired normal tissues (resected $6-\mathrm{cm}$ from the cancerous tissues) were collected from each participant. For RNA extraction, the specimens resected during surgery were immediately snap-frozen in liquid nitrogen and subsequently stored at $-80^{\circ} \mathrm{C}$, followed by fixing in $10 \%$ buffered formalin (Sigma Aldrich; EMD Millipore, Billerica, MA, USA) for $24 \mathrm{~h}$ and embedding in paraffin (Sigma-Aldrich; EMD Millipore). To investigate the association between KPNA2 expression, clinicopathological features and survival of CRC patients following radical surgery, a larger sample size was required. Therefore, an additional 300 patients with CRC that underwent radical resection at The Second Affiliated Hospital of Harbin Medical University (Harbin, China) between January 2007 and December 2008 were included in the present study. Patients that had received preoperative chemotherapy or irradiation were excluded. Tumors were staged according to the Union for International Cancer Control staging system. The patient cohort included 175 men and 125 women (mean age, 62.1 years; range, 23-83 years). Cancerous tissues and paired normal tissues were excised and fixed in $10 \%$ buffered formalin for $24 \mathrm{~h}$ and embedded in paraffin blocks. For all samples, histological diagnosis was performed by three independent and experienced pathologists.
Immunohistochemical analysis. Tissue samples underwent immunohistochemical analysis using the avidin-biotin-peroxidase method. Sections were deparaffinized in xylene (Sigma-Aldrich; EMD Millipore) and dehydrated using graded alcohol prior to endogenous peroxidase activity blocking using $0.5 \%$ hydrogen peroxide (Sigma-Aldrich; EMD Millipore) in methanol (Sigma-Aldrich; EMD Millipore) for $10 \mathrm{~min}$. Non-specific binding was blocked by incubating tissue sections with $10 \%$ normal goat serum (Sigma-Aldrich; EMD Millipore) in phosphate-buffered saline (PBS) for $1 \mathrm{~h}$ at room temperature. The sections were subsequently incubated with polyclonal human KPNA2 antibody (dilution, 1:300; catalog no., 10819-1-AP; Proteintech, Inc., Wuhan, China) in PBS at $4^{\circ} \mathrm{C}$ overnight, followed by $1 \mathrm{~h}$ of incubation with biotinylated goat anti-mouse immunoglobulin G (IgG; ZDR 5210; dilution, 1:400; ZSGB-BIO, Beijing, China) at room temperature. Subsequently, sections were treated with streptavidin-peroxidase for $10 \mathrm{~min}$ at room temperature (Sigma-Aldrich; EMD Millipore). Sections were then incubated with $0.1 \%$ 3,3'-diaminobenzidine (ZSGB-BIO) in PBS with $0.05 \%$ hydrogen peroxide for $5 \mathrm{~min}$ at room temperature. All tissue specimens were assessed separately by two pathologists blinded to the clinicopathological data. KPNA2 expression in CRC specimens was evaluated microscopically (Nikon ECLIPSE Ti-E; Nikon Corporation, Tokyo, Japan) at low magnification (x40) and the results were confirmed at high magnifications (x200 and $\mathrm{x} 400$ ) by two surgical pathologists blinded to the clinical data. An immunoreactivity scoring system was applied, according to previously reported procedures (12). The percentage of positive cells was scored as follows: 0 ( $<5 \%$, negative); 1 (5-25\%, sporadic); 2 (25-50\%, focal); and 3 ( $>50 \%$, diffuse). The staining intensity was scored as follows: 0 , no staining; 1, weak staining; 2, moderate staining; and 3, strong staining. The KPNA2 immunostaining score was calculated using the following formula: Immunostaining score $=$ positive cell score $\mathrm{x}$ staining intensity score. The immunostaining score ranged between 0 and 9 . A score of $\geq 4$ indicated high KPNA2 expression.

$R T-q P C R$. Total RNA was extracted from tissue samples using TRIzol reagent (Invitrogen; Thermo Fisher Scientific, Inc., Waltham, MA, USA) according to the manufacturer's protocol. First-strand complementary DNA (cDNA) was synthesized using $1 \mu \mathrm{g}$ total RNA and a RevertAid ${ }^{\mathrm{TM}} \mathrm{H}$ Minus First Strand cDNA Synthesis kit (Fermentas Inc., Burlington, ON, Canada) according to the manufacturer's protocol. The primers for KPNA2 and glyceraldehyde-3-phosphate dehydrogenase (GAPDH; internal control) were obtained from Takara Biotechnology Co., Ltd., (Dalian, China), with the following sequences: forward 5'-CAAGGCTGTGGTAGA TGG-3' and reverse, 5'-GCGGCAAAGATTAGAAAG-3' for KPNA2; forward, 5'-CAATGACCCCTTCATTGACC-3' and reverse, 5'-GACAAGCTTCCCGTTCTCAG-3' for GAPDH. The KPNA2 and GAPDH genes were amplified from the cDNA pool using gene-specific primers and the Power SYBR Green PCR Master Mix (Applied Biosystems; Thermo Fisher Scientific, Inc.) in an ABI PRISM 7500 Sequence Detection System (Applied Biosystems; Thermo Fisher Scientific, Inc.). PCR was performed under the following conditions: Initial denaturation at $95^{\circ} \mathrm{C}$ for 5 min followed by 40 cycles of $94^{\circ} \mathrm{C}$ 
Table I. KPNA2 expression in 300 colorectal cancer and paired normal tissues.

\begin{tabular}{lcccr}
\hline & \multicolumn{2}{c}{ KPNA2 expression ${ }^{\mathrm{a}}, \mathrm{n}(\%)$} & & \\
\cline { 2 - 4 } Tissue type & Positive & Negative & $\chi^{2}$ & P-value $^{\mathrm{b}}$ \\
\hline Colorectal cancer & $272(90.7)$ & $28(9.3)$ & 347.55 & $<0.001$ \\
Paired normal & $44(14.7)$ & $256(85.3)$ & & \\
\hline
\end{tabular}

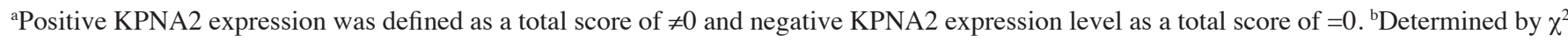
test. KPNA2, karyopherin $\alpha 2$.
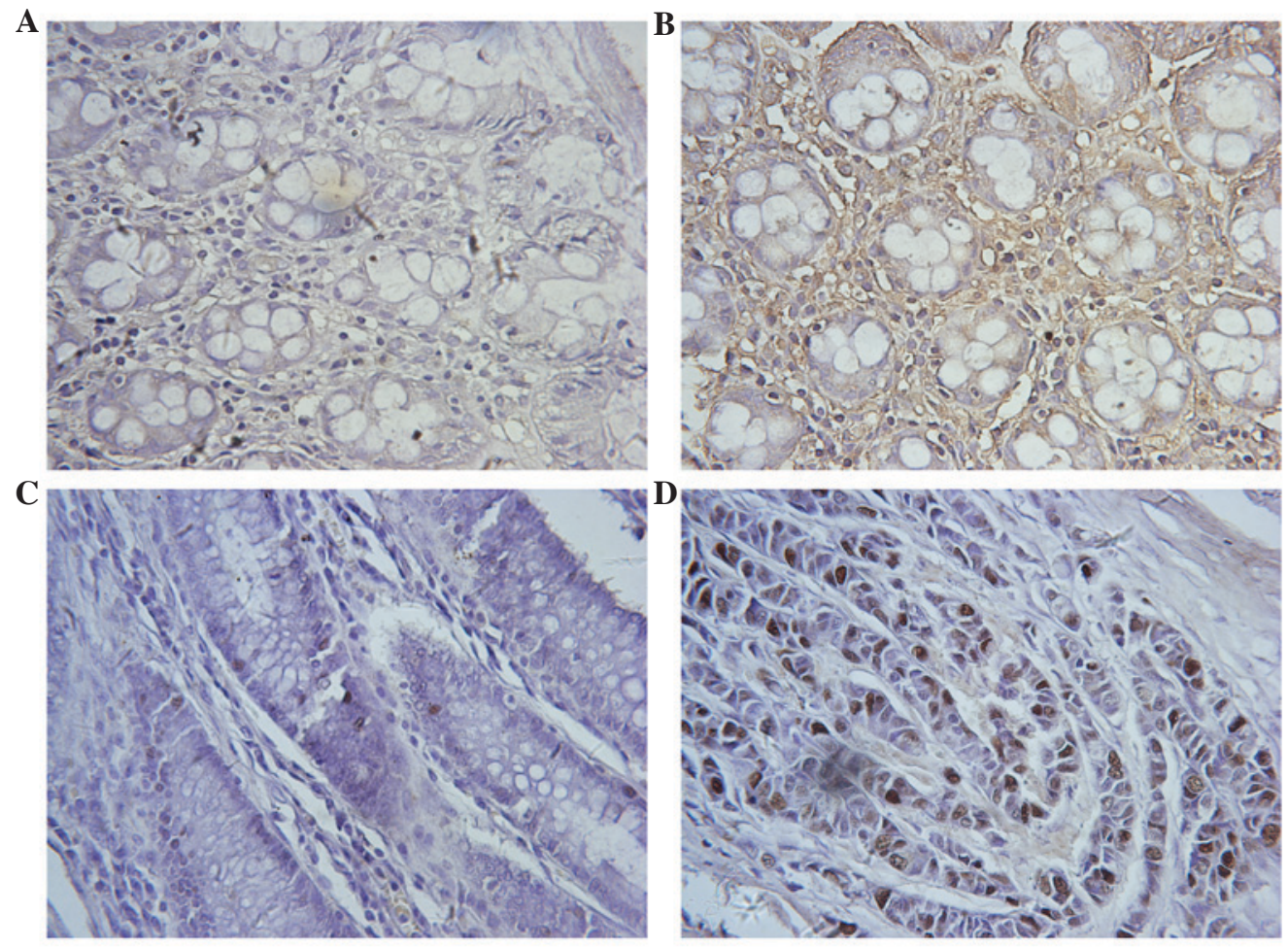

Figure 1. Immunohistochemical KPNA2 staining in colorectal tissue. Normal adjacent colorectal tissue specimens exhibiting (A) negative and (B) low KPNA2 expression (magnification, x400). Colorectal cancer tissues exhibiting (C) low and (D) high KPNA2 expression (magnification, x200). KPNA2, karyopherin 02 .

for $20 \mathrm{sec}, 58^{\circ} \mathrm{C}$ for $20 \mathrm{sec}$ and $72^{\circ} \mathrm{C}$ for $20 \mathrm{sec}$. RT-qPCR was performed at least three times, and a negative control group was also used. KPNA2 and GAPDH were amplified in an identical reaction. The expression of the target gene was evaluated using the $2^{-\Delta \Delta \mathrm{Cq}}$ method for relative quantification using GAPDH as the internal reference gene (7).

Fluorometric sandwich ELISA. KPNA2 protein levels in human serum were determined using the KPNA2 ELISA kit (Shanghai BlueGene Biotech Co., Ltd., Shanghai, China). The serum from patients and healthy volunteers were incubated with a KPNA2-horseradish peroxidase (HRP) conjugate (dilution, 1:5,000; ZSR 5210) in a pre-coated plate (coated with HRP-conjugated rabbit antibody) at $37^{\circ} \mathrm{C}$ for $1 \mathrm{~h}$. Following incubation, the wells were emptied and washed 5 times with wash solution (PBS and Tween 20). The wells were subsequently incubated with a substrate for HRP enzyme at $37^{\circ} \mathrm{C}$ for $15 \mathrm{~min}$ and subsequently a blue-colored complex was formed due to the enzyme-substrate reaction. Finally, a stop solution $\left(1 \mathrm{M} \mathrm{H}_{2} \mathrm{SO}_{4}\right.$ ) was added to terminate the reaction, as signified by a color change from blue to yellow. The intensity of the yellow color was measured spectrophotometrically at a wavelength of $450 \mathrm{~nm}$ using a Thermo Multiskan MK3 microplate reader (Thermo Fisher Scientific, Inc.). The intensity of the color was inversely proportional to the KPNA2 concentration: As KPNA2 binds more sites in the serum, fewer sites remain for KPNA2-HRP conjugate binding. A standard curve was plotted correlating the intensity of the color (optical density) with the concentration. The KPNA2 concentration in each sample was interpolated based on the standard curve.

Statistical analysis. Data were analyzed using SPSS version 17.0 (SPSS Inc., Chicago, IL, USA). All continuous variables were expressed as the mean \pm standard deviation. The nonparametric Mann-Whitney $U$ test was utilized to analyze variations in ELISA results. $\chi^{2}$ test was applied to 


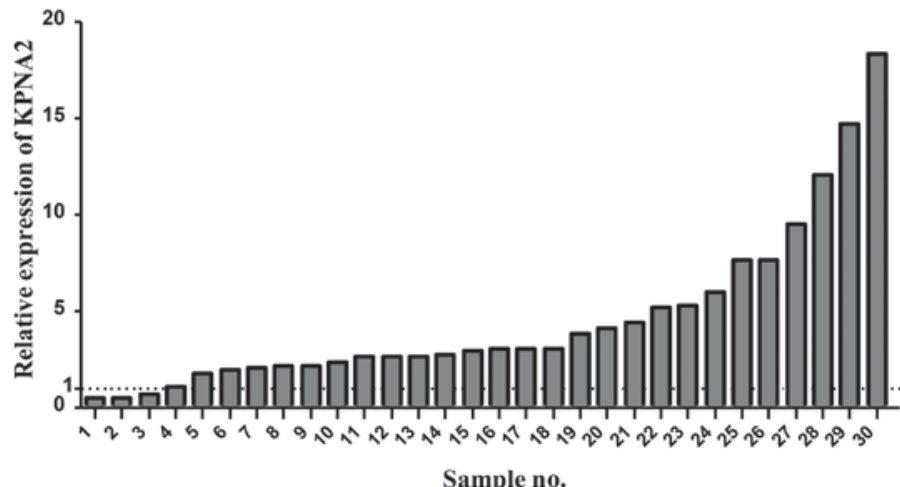

Figure 2. Relative KPNA2 expression in $30 \mathrm{CRC}$ tissues compared with normal tissues was analyzed by reverse transcription-quantitative polymerase chain reaction. Relative KPNA2 expression was significantly increased in CRC tissues compared with paired normal tissues ( $<<0.001)$. KPNA2, karyopherin $\alpha 2$; $\mathrm{CRC}$, colorectal cancer.

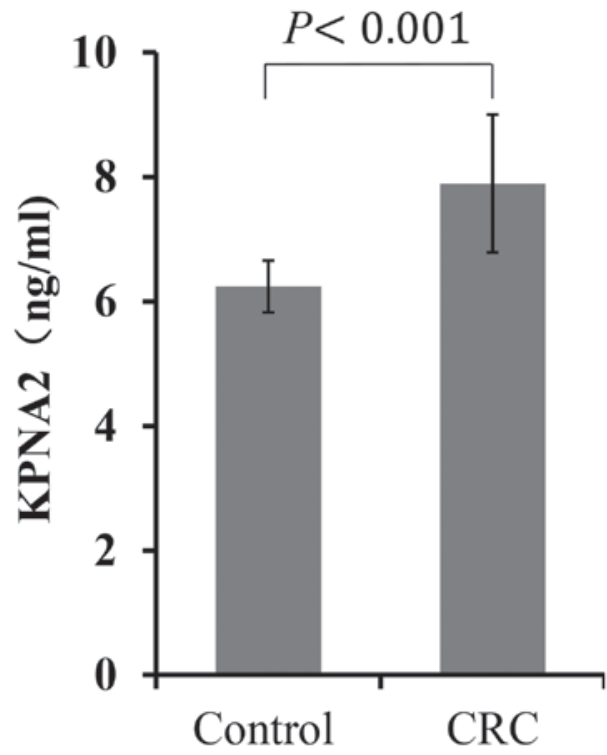

Figure 3. Preoperative serum KPNA2 expression levels were analyzed by enzyme-linked immunosorbent assay in 30 CRC patients and 10 healthy individuals. Serum KPNA2 expression levels were significantly increased in CRC patients compared with healthy individuals $(7.84 \pm 1.11 \mathrm{ng} / \mathrm{ml} \mathrm{vs}$ $6.24 \pm 0.42 \mathrm{ng} / \mathrm{ml} ; \mathrm{P}<0.001)$. KPNA2, karyopherin $\alpha 2 ; \mathrm{CRC}$, colorectal cancer.

evaluate the statistical significance of the association between KPNA2 expression and other clinicopathological variables. For univariate survival analysis, survival curves were calculated according to the Kaplan-Meier method. The difference in survival rates was assessed using the log-rank test. Cox's proportional hazard model was utilized to identify factors that exhibited a significant influence on survival. $\mathrm{P}<0.05$ was considered to indicate a statistically significant difference.

\section{Results}

KPNA2 is overexpressed in CRC tissues compared with paired normal tissues. Immunohistochemistry identified nuclear KPNA2 expression in the majority of cells of the cancer tissues examined (26/30 samples), and a small number of paired normal tissues (Fig. 1). In general, CRC tissues exhibited a markedly increased KPNA2 expression rate compared with paired normal tissues. KPNA2 expression

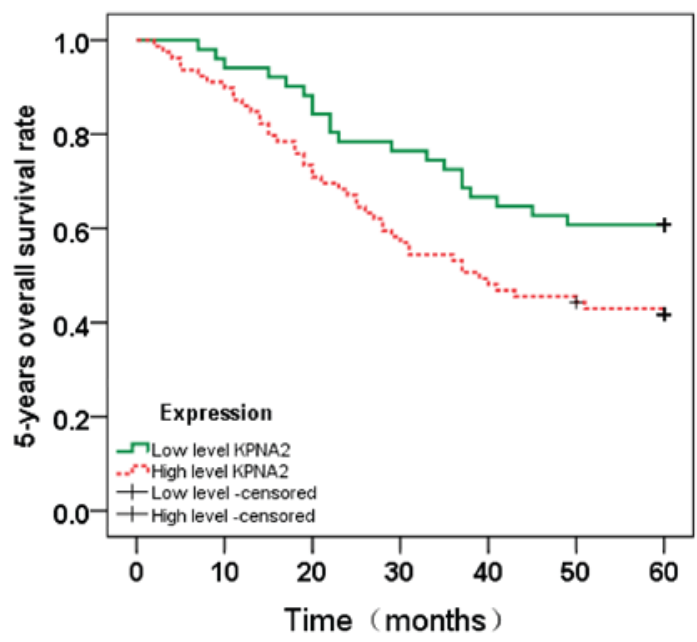

Figure 4. Kaplan-Meier survival curves illustrating the correlation between KPNA2 expression and 5-year OS in CRC patients. CRC patients with low KPNA2 expression levels exhibited longer OS times compared with patients exhibiting high KPNA2 expression levels $\left(\chi^{2}=4.97\right.$; $\left.=0.026\right)$. KPNA2, karyopherin $\alpha 2$; OS, overall survival; CRC, colorectal cancer.

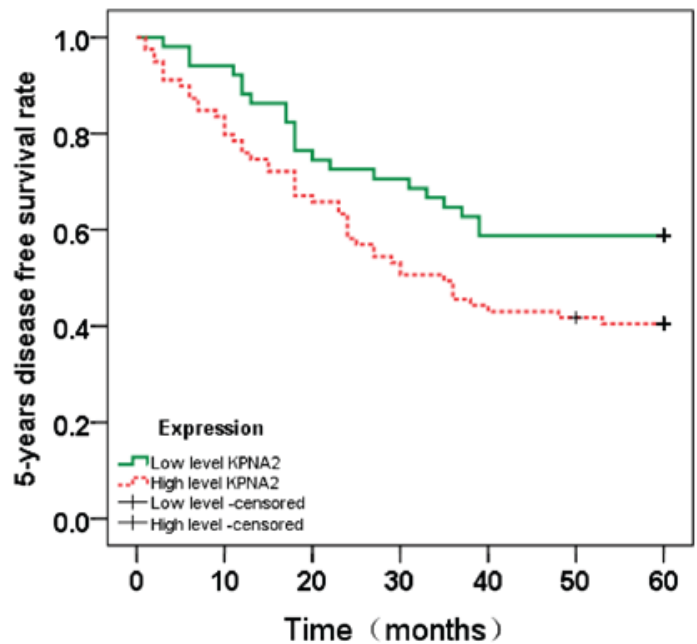

Figure 5. Kaplan-Meier survival curves illustrating the correlation between KPNA2 expression and 5-year DFS in CRC patients. CRC patients with low KPNA2 expression levels exhibited increased 5-year DFS rates compared with those exhibiting high KPNA2 expression levels $\left(\chi^{2}=4.36 ; \mathrm{P}=0.037\right)$. KPNA2, karyopherin $\alpha 2$; DFS, disease-free survival; CRC, colorectal cancer. 
Table II. Associations between KPNA2 expression and patient clinicopathological features were analyzed in 300 colorectal cancer patients.

\begin{tabular}{|c|c|c|c|c|}
\hline Parameter & $\begin{array}{c}\text { High KPNA2 } \\
\text { expression }{ }^{\mathrm{a}}, \mathrm{n}(\%)\end{array}$ & $\begin{array}{c}\text { Low KPNA2 } \\
\text { expression }^{\mathrm{a}}, \mathrm{n}(\%)\end{array}$ & $z^{2}$ & P-value \\
\hline \multicolumn{5}{|l|}{ Gender } \\
\hline Male & $110(36.67)$ & $65(21.67)$ & \multirow[t]{2}{*}{0.84} & \multirow[t]{2}{*}{$0.358^{\mathrm{b}}$} \\
\hline Female & $72(24.00)$ & 53 (17.67) & & \\
\hline \multicolumn{5}{|l|}{ Age, years } \\
\hline$\leq 60$ & $78(26.00))$ & $58(19.33)$ & \multirow[t]{2}{*}{1.15} & \multirow[t]{2}{*}{$0.285^{\mathrm{b}}$} \\
\hline$>60$ & $104(34.67)$ & $60(20.00)$ & & \\
\hline \multicolumn{5}{|l|}{ Tumor size, cm } \\
\hline$<5$ & $117(39.00)$ & $81(27.00)$ & \multirow[t]{2}{*}{0.61} & \multirow[t]{2}{*}{$0.457^{\mathrm{b}}$} \\
\hline$\geq 5$ & 65 (21.67) & $37(12.33)$ & & \\
\hline \multicolumn{5}{|l|}{ Differentiation } \\
\hline Well & $15(5.00)$ & $26(8.67)$ & \multirow[t]{3}{*}{12.56} & \multirow[t]{3}{*}{$0.020^{\mathrm{b}, \mathrm{d}}$} \\
\hline Moderate & 119 (39.67) & $71(23.67)$ & & \\
\hline Poor & $48(16.00)$ & $21(7.00)$ & & \\
\hline \multicolumn{5}{|l|}{ TNM stage } \\
\hline I & $17(5.67)$ & $20(6.67)$ & \multirow[t]{4}{*}{16.86} & \multirow[t]{4}{*}{$0.001^{\mathrm{c}, \mathrm{d}}$} \\
\hline II & $85(28.33)$ & $69(23.00)$ & & \\
\hline III & $53(17.67)$ & $25(8.33)$ & & \\
\hline IV & $27(9.00)$ & $4(1.33)$ & & \\
\hline \multicolumn{5}{|l|}{ Infiltration depth } \\
\hline $\mathrm{T} 1+\mathrm{T} 2$ & $23(7.67)$ & $29(9.67)$ & \multirow[t]{2}{*}{6.66} & \multirow[t]{2}{*}{$0.012^{\mathrm{b}, \mathrm{d}}$} \\
\hline $\mathrm{T} 3+\mathrm{T} 4$ & $155(51.67)$ & $89(30.07)$ & & \\
\hline \multicolumn{5}{|c|}{ Lymph node involvement, $\mathrm{n}$} \\
\hline 0 & $102(34.00)$ & $97(32.33)$ & \multirow[t]{2}{*}{21.94} & \multirow[t]{2}{*}{$<0.001^{\mathrm{b}, \mathrm{c}}$} \\
\hline$\geq 1$ & $80(26.67)$ & $21(7.00)$ & & \\
\hline \multicolumn{5}{|l|}{ LVI or PNI } \\
\hline Negative & $65(21.67)$ & $67(22.33)$ & \multirow[t]{2}{*}{12.89} & \multirow[t]{2}{*}{$<0.001^{\mathrm{b},}$} \\
\hline Positive & $117(39.00)$ & $51(17.00)$ & & \\
\hline \multicolumn{5}{|l|}{ Tumor location } \\
\hline Right-side colon & $69(23.00)$ & $42(14.00)$ & \multirow[t]{3}{*}{2.38} & \multirow[t]{3}{*}{$0.312^{\mathrm{b}}$} \\
\hline Left-side colon & $60(20.00)$ & $32(10.67)$ & & \\
\hline Rectum & $53(17.67)$ & $44(14.67)$ & & \\
\hline
\end{tabular}

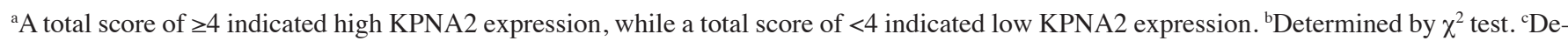
termined by Fisher's exact test. ${ }^{\mathrm{d}} \mathrm{P}<0.05$. Clinicopathological features were assessed according to the Union for International Cancer Control. KPNA2, karyopherin $\alpha 2$; PNI, perineural invasion; LVI, lymphovascular invasion; TNM, Tumor-Node-Metastasis.

was identified in 272/300 (90.7\%) CRC tissues, and low KPNA2 expression was observed in 44/300 (14.7\%) paired normal tissues $(\mathrm{P}<0.001$; Table I), while no KPNA2 expression was observed in 256/300 paired normal tissues (Fig. 1A). KPNA2 expression in 30 human CRC tissues and paired normal tissues was measured by RT-qPCR. A total of 26/30 (86.7\%) CRC samples exhibited increased KPNA2 expression compared with normal tissues. Relative KPNA2 expression was significantly increased in colorectal adenocarcinoma tissues compared with paired normal tissues $(\mathrm{P}<0.001$; Fig. 2). These results demonstrate that KPNA2 expression is significantly increased in cancer tissues compared with paired normal tissues.
KPNA2 serum levels are increased in CRC patients. To investigate the preoperative diagnostic value of KPNA2 expression for CRC, ELISA was used to analyze KPNA2 expression in the serum of $30 \mathrm{CRC}$ patients and 10 healthy individuals. As shown in Fig. 3, the serum KPNA2 levels were significantly increased in CRC patients compared with healthy individuals (7.84 $\pm 1.11 \mathrm{ng} / \mathrm{ml}$ vs. 6.24 \pm 0.42 ng/ml; $\mathrm{P}<0.001$; Fig. 3).

Correlation between KPNA2 expression and patient clinicopathological features. The associations between KPNA2 expression and clinicopathological features, including age, gender, tumor size, differentiation, Tumor-Node-Metastasis (TNM) stage, infiltration depth, lymph node involvement, 
lymphovascular invasion (LVI), perineural invasion (PNI) and tumor location of CRC patients, are shown in Table II. High KPNA2 expression was significantly associated with lymph node involvement $(\mathrm{P}<0.001)$, LVI and PNI $(\mathrm{P}<0.001)$ in $\mathrm{CRC}$ patients. In addition, KPNA2 expression was significantly associated with tumor differentiation $(\mathrm{P}=0.020)$, infiltration depth $(\mathrm{P}=0.012)$ and TNM stage $(\mathrm{P}=0.001)$. The results additionally demonstrated that the intensity of KPNA2 expression was increased in late-stage patients compared with those with early-stage CRC. However, no significant differences were identified between KPNA2 expression and age $(\mathrm{P}=0.285)$, gender $(\mathrm{P}=0.358)$, tumor size $(\mathrm{P}=0.457)$ or tumor location $(\mathrm{P}=0.312)$ in $\mathrm{CRC}$ patients.

Survival analysis. To evaluate the prognostic value of KPNA2 for CRC, the association between KPNA2 expression and patient survival time was analyzed using the Kaplan-Meier method with a log-rank test (Figs. 4 and 5). Nuclear KPNA2 expression was significantly associated with overall survival $(\mathrm{OS} ; \mathrm{P}=0.026)$ and disease-free survival (DFS; $\mathrm{P}=0.037$ ). Overall, higher KPNA2 expression was associated with shorter OS and DFS times in CRC patients.

\section{Discussion}

The present study revealed that KPNA2 expression is upregulated in primary tumors and the serum of CRC patients. The level of KPNA2 expression was associated with certain clinicopathological features, including lymph node involvement, LVI, PNI, tumor differentiation, infiltration depth and TNM stage. Furthermore, high levels of KPNA2 expression were observed to correlate with shorter survival times in CRC patients following radical surgery.

The exchange of molecules between the nucleus and cytoplasm is mediated by large nuclear pore complexes (2). Karyopherins are involved in this process when molecules are $>40 \mathrm{kDa}(8)$, acting as carrier proteins in a selective bidirectional shuttling process (8). In cancer cells, cellular transport dysfunction is common (8).

In 2006, Dahl et al (9) reported that KPNA2 expression exhibited prognostic value in breast cancer, and this was subsequently demonstrated in a variety of other malignancies, including prostate and gastric cancer (10-18). In recent years, KPNA2 has gained attention as a potential biomarker for several types of cancer, including lung cancer. The increased KPNA2 expression observed in cancer tissues is predominantly localized to the cell nucleus. This may be due to cellular stress, including oxidative stress and heat shock, which may lead to the accumulation of KPNA2 in the nucleus of tumor cells. It has been reported that cells in advanced tumors typically exhibit a high level of oxidative stress (19-25).

KPNA2 overexpression in cancer tissues has been associated with increased morbidity $(7,13)$. The majority of previous studies have shown that increased KPNA2 expression is correlated with a poor prognosis $(7,9,13)$. Other studies have implicated KPNA2 as an independent prognostic factor for patients with breast and lung cancer (9,15-17). Similarly, Kaplan-Meier survival analysis performed in the present study revealed that KPNA2 expression in primary tumors is a powerful predictive factor for CRC patients. Therefore, these results indicate that measuring KPNA2 expression may allow physicians to diagnose CRC patients with a poor prognosis. This may lead to better individualized risk stratification and thus, may optimize therapy for CRC patients.

Due to its involvement in molecular transport and as a tumor marker, KPNA2 has a role in a number of biological processes, including cellular proliferation, differentiation, cellular matrix adhesion, colony formation and migration $(4,13,15,26-28)$. Recent evidence has indicated that KPNA2 may regulate cancer cell transformation (26). KPNA2 expression in cancer tissues is typically 5-10-fold higher than that in normal tissue at the transcriptional level $(10,14)$. These differences in KPNA2 expression were additionally observed in the present study, which supports the hypothesis that KPNA2 possesses a significant role in CRC carcinogenesis. Certain viruses cause their host cells to proliferate uncontrollably (28). Such viruses, often termed tumor viruses, may lead to carcinogenesis (28). Notably, a previous study revealed that human papilloma virus, BK virus and Simian virus 40 are capable of inducing chromosomal instability and contributing to CRC development by altering cell cycle control and inhibiting apoptosis (29). KPNA2 has been reported to be involved in tumor viral infections, primarily by transporting viruses, including Epstein-Barr virus (30), human papillomavirus $(31,32)$, polyomavirus (33) and human immunodeficiency virus (34), into the nucleus. These previous studies (30-34) demonstrated that viruses infected the normal host cells and led to cell carcinogenesis via the KPNA2 signaling pathway (27). Furthermore, KPNA2 is hypothesized to function in the regulation of viral capsid assembly (35). It has additionally been postulated that KPNA2 may import DNA repair proteins and cell cycle control proteins, including breast cancer 1 and Nijmegen breakage syndrome 1 (36-38). In addition, KPNA2 has been implicated in the cellular processes of the carcinogenesis of various types of cancer (38). KPNA2 expression has been associated with numerous differentiation processes. In embryonic stem cells obtained from mice, due to promoter activation by Krüppel-like factor (Klf)2 and Klf4, high expression of KPNA2 was observed (39). Silencing of KPNA2 has been shown to suppress the migration and proliferation of lung cancer cells, indicating the significance of KPNA2 in tumorigenesis (13).

The present study revealed that KPNA2 expression is associated with CRC tumor stage. Furthermore, it has been demonstrated that KPNA2 expression is positively correlated with lymph node metastasis and venous infiltration $(9,11,14-17,40-42)$. A previous study suggested that KPNA2 exhibits a significant role in the malignant transformation of cancer cells (27). Thus, KPNA2 may serve as a novel diagnostic factor for early stage cancer.

In conclusion, the present study revealed that KPNA2 is overexpressed during the malignant tumor progression of CRC. In addition, univariate analyses demonstrated that increased KPNA2 expression was associated with shortened survival times in CRC patients that had undergone radical surgery. Further molecular biological experiments are required to investigate the mechanism by which high levels of KPNA2 expression promote the progression of CRC. 


\section{Acknowledgements}

This paper was supported by the Foundation of Heilongjiang Academy of Medical Science (grant no. 201601).

\section{References}

1. Brenner H, Kloor M and Pox CP: Colorectal cancer. Lancet 65: 1490-1502, 2014.

2. Kau TR, Way JC and Silver PA: Nuclear transport and cancer: From mechanism to intervention. Nat Rev Cancer 4: 106-117, 2004.

3. Goldfarb DS, Corbett AH, Mason DA, Harreman MT and Adam SA: Importin alpha: A multipurpose nuclear-transport receptor. Trends Cell Biol 14: 505-514, 2004.

4. Christiansen A and Dyrskjøt L: The functional role of the novel biomarker karyopherin $\alpha 2$ (KPNA2) in cancer. Cancer Lett 331: 18-23, 2013.

5. Radu A, Blobel G and Moore MS: Identification of a protein complex that is required for nuclear protein import and mediates docking of import substrate to distinct nucleoporins. Proc Natl Acad Sci USA 92: 1769-1773, 1995.

6. Kotera I, Sekimoto T, Miyamoto Y, Saiwaki T, Nagoshi E, Sakagami H, Kondo H and Yoneda Y: Importin alpha transports CaMKIV to the nucleus without utilizing importin beta. EMBO J 24: 942-951, 2005.

7. Stewart M: Molecular mechanism of the nuclear protein import cycle. Nat Rev Mol Cell Biol 8: 195-208, 2007.

8. Livak and Schmittgen: Analysis of relative gene expression data using real-time quantitative PCR and the $2-\Delta \Delta \mathrm{Ct}$ method. Methods 25: 402-408, 2001.

9. Dahl E, Kristiansen G, Gottlob K, Klaman I, et al: Molecular profiling of laser-microdissected matched tumor and normal breast tissue identifies karyopherin alpha2 as a potential novel prognostic marker in breast cancer. Clin Cancer Res 12: 3950-3960, 2006.

10. van der Watt PJ, Maske CP, Hendricks DT, Parker MI, Denny L, Govender D, Birrer MJ and Leaner VD: The Karyopherin proteins, Crm1 and Karyopherin beta1, are overexpressed in cervical cancer and are critical for cancer cell survival and proliferation. Int $\mathrm{J}$ Cancer 124: 1829-1840, 2009

11. Sakai M, Sohda M, Miyazaki T, Suzuki S, Sano A, Tanaka N, Inose T, Nakajima M, Kato $\mathrm{H}$ and Kuwano $\mathrm{H}$ : Significance of karyopherin-\{alpha\} 2 (KPNA2) expression in esophageal squamous cell carcinoma. Anticancer Res 30: 851-856, 2010.

12. Winnepenninckx V, Lazar V, Michiels S, Dessen P, Stas M, Alonso SR, Avril MF, Ortiz Romero PL, Robert T, Balacescu O, et al: Gene expression profiling of primary cutaneous melanoma and clinical outcome. J Natl Cancer Inst 98: 472-482, 2006.

13. Wang CI, Wang CL, Wang CW, Chen CD, Wu CC, Liang Y, Tsai YH, Chang YS, Yu JS and Yu CJ: Importin subunit alpha-2 is identified as a potential biomarker for non-small cell lung cancer by integration of the cancer cell secretome and tissue transcriptome. Int J Cancer 128: 2364-2372, 2011.

14. Li C, Ji L, Ding ZY, Zhang QD and Huang GR: Overexpression of KPNA2 correlates with poor prognosis in patients with gastric adenocarcinoma. Tumour Biol 34: 1021-1026, 2013.

15. Mortezavi A, Hermanns T, Seifert HH, et al: KPNA2 expression is an independent adverse predictor of biochemical recurrence after radical prostatectomy. Clin Cancer Res 17: 1111-1121, 2011.

16. Gousias K, Becker AJ, Simon M and Niehusmann P: Nuclear karyopherin a2: A novel biomarker for infiltrative astrocytomas. J Neurooncol 109: 545-553, 2012.

17. Yoshitake K, Tanaka S, Mogushi K, et al: Importin- $\alpha 1$ as a novel prognostic target for hepatocellular carcinoma. Ann Surg Oncol 18: 2093-2103, 2011.

18. He L, Ding H, Wang JH, et al: Overexpression of karyopherin 2 in human ovarian malignant germ cell tumor correlates with poor prognosis. PLoS One 7: e42992, 2012.

19. Stochaj U, Rassadi R and Chiu J: Stress-mediated inhibition of the classical nuclear protein import pathway and nuclear accumulation of the small GTPase Gsplp. FASEB J 14: 2130-2132, 2000.

20. Furuta M, Kose S, Koike M, et al: Heat-shock induced nuclear retention and recycling inhibition of importin alpha. Genes Cells 9 : 429-441, 2004

21. Kodiha M, Chu A, Matusiewicz N and Stochaj U: Multiple mechanisms promote the inhibition of classical nuclear import upon exposure to severe oxidative stress. Cell Death Differ 11: $862-874,2004$
22. Miyamoto Y, Saiwaki T, Yamashita J, Yasuda Y, Kotera I, Shibata S, Shigeta M, Hiraoka Y, Haraguchi T and Yoneda Y: Cellular stresses induce the nuclear accumulation of importin alpha and cause a conventional nuclear import block. J Cell Biol 165: 617-623, 2004

23. Trachootham D, Alexandre J and Huang P: Targeting cancer cells by ROS-mediated mechanisms: A radical therapeutic approach? Nat Rev Drug Discov 8: 579-591, 2009.

24. Yasuda Y, Miyamoto Y, Yamashiro T, Asally M, Masui A, Wong C, Loveland KL and Yoneda Y: Nuclear retention of importin $\alpha$ coordinates cell fate through changes in gene expression. EMBO J 31: 83-94, 2012.

25. Miyamoto Y, Loveland KL and Yoneda Y: Nuclear importin $\alpha$ and its physiological importance. Commun Integr Biol 5: 220-222, 2012 .

26. Umegaki N, Tamai K, Nakano H, Moritsugu R, Yamazaki T, Hanada K, Katayama I and Kaneda Y: Differential regulation of karyopherin alpha 2 expression by TGF-beta1 and IFN-gamma in normal human epidermal keratinocytes: Evident contribution of KPNA2 for nuclear translocation of IRF-1. J Invest Dermatol 127: 1456-1464, 2007.

27. Noetzel E, Rose M, Bornemann J, Gajewski M, Knüchel R and Dahl E: Nuclear transport receptor karyopherin- $\alpha 2$ promotes malignant breast cancer phenotypes in vitro. Oncogene 31: 2101-2114, 2012

28. Hall MN, Griffin CA, Simionescu A, Corbett AH and Pavlath GK: Distinct roles for classical nuclear import receptors in the growth of multinucleated muscle cells. Dev Biol 357: 248-258, 2011.

29. Giuliani L, Ronci C, Bonifacio D, Di Bonito L, Favalli C, Perno CF, Syrjänen K and Ciotti M: Detection of oncogenic DNA viruses in colorectal cancer. Anticancer Res 28: 1405-1410, 2008.

30. Fischer N, Kremmer E, Lautscham G, Mueller-Lantzsch N and Grässer FA: Epstein-Barr virus nuclear antigen 1 forms a complex with the nuclear transporter karyopherin alpha2. J Biol Chem 272: 3999-4005, 1997

31. Nelson LM, Rose RC, LeRoux L, Lane C, Bruya K and Moroianu J: Nuclear import and DNA binding of human papillomavirus type $45 \mathrm{~L} 1$ capsid protein. J Cell Biochem 79: 225-238, 2000.

32. Le Roux LG and Moroianu J: Nuclear entry of high-risk human papillomavirus type 16 E6 oncoprotein occurs via several pathways. J Virol 77: 2330-2337, 2003.

33. Qu Q, Sawa H, Suzuki T, Semba S, Henmi C, Okada Y, Tsuda M, Tanaka S, Atwood WJ and Nagashima K: Nuclear entry mechanism of the human polyomavirus JC virus-like particle: Role of importins and the nuclear pore complex. J Biol Chem 279: 27735-27742, 2004

34. Gallay P, Stitt V, Mundy C, Oettinger M and Trono D: Role of the karyopherin pathway in human immunodeficiency virus type 1 nuclear import. J Virol 70: 1027-1032, 1996.

35. Bird G, O'Donnell M, Moroianu J and Garcea RL: Possible role for cellular karyopherins in regulating polyomavirus and papillomavirus capsid assembly. J Virol 82: 9848-9857, 2008.

36. Narod SA and Foulkes WD: BRCA1 and BRCA2: 1994 and beyond. Nat Rev Cancer 4: 665-676, 2004.

37. Teng SC, Wu KJ, Tseng SF, Wong CW and Kao L: Importin KPNA2, NBS1, DNA repair and tumorigenesis. J Mol Histol 37: 293-299, 2006.

38. Cutress ML, Whitaker HC, Mills IG, Stewart M and Neal DE: Structural basis for the nuclear import of the human androgen receptor. J Cell Sci 121: 957-968, 2008.

39. Kamikawa Y, Yasuhara N and Yoneda Y: Cell type-specific transcriptional regulation of the gene encoding importin-alpha1. Exp Cell Res 317: 1970-1978, 2011.

40. Dankof A, Fritzsche FR, Dahl E, Pahl S, Wild P, Dietel M, Hartmann A and Kristiansen G: KPNA2 protein expression in invasive breast carcinoma and matched peritumoral ductal carcinoma in situ. Virchows Arch 451: 877-881, 2007.

41. Gluz O, Wild P, Meiler R, Diallo-Danebrock R, Ting E, Mohrmann S, Schuett G, Dahl E, Fuchs T, Herr A, et al: Nuclear karyopherin alpha 2 expression predicts poor survival in patients with advanced breast cancer irrespective of treatment intensity. Int J Cancer 123: 1433-1438, 2008

42. Altan B, Yokobori T, Mochiki E, Ohno T, Ogata K, Ogawa A, Yanai M, Kobayashi T, Luvsandagva B, Asao T and Kuwano H: Nuclear karyopherin- $\alpha 2$ expression in primary lesions and metastatic lymph nodes was associated with poor prognosis and progression in gastric cancer. Carcinogenesis 34: 2314-2321, 2013. 